\title{
Post-operatif Ortopedik Rehabilitasyonda Yeni Egzersiz İzlem ve Yönetim Teknolojileri
}

\author{
New Exercise Monitoring and Management Technologies in Post-Operative \\ Orthopaedic Rehabilitation
}

Fatih ÖZDEN'10

${ }^{1}$ Muğla Sıtkı Koçman Üniversitesi Yaşlı Bakımı Bölümü, Muğla, Türkiye

ÖZ

\begin{abstract}
Post-operatif ortopedik rehabilitasyon sürecinde, egzersiz protokollerinin uygun şekilde gerçekleştirilmesi, hastanın klinik durumunda elde edilecek iyileşme açısından büyük önem taşımaktadır. Son yıllarda telerehabilitasyon hizmetlerinin yaygınlaşmasıyla birlikte, klinisyenlerin hastalarına ait egzersiz protokollerini izlem ve yönetimi daha pratik, maliyeti düşük ve zamandan tasarruf edilecek şekilde mümkün olabilmektedir. Total diz artroplastisi başta olmak üzere birçok patolojik durumda post-operatif dönemde telerehabilitasyonun kullanıldı $\breve{g}$, randomize kontrollü çalışmalarla etkinliğinin araştırıldı $\breve{g ̆}_{1}$ görülmektedir. Bu derlemede post-operatif ortopedik rehabilitasyon sürecinde egzersiz izlem ve yönetim teknolojileri ele alınmıştır. Bu uygulamaların konvansiyonel yöntemlere göre farkları, benzerlikleri, avantajları ve dezavantajları incelenecektir.
\end{abstract}

Anahtar Kelimeler: Ortopedik Rehabilitasyon, Telerehabilitasyon, Egzersiz, Post-Operatif.

ABSTRACT

Appropriate application of exercise protocols during post-operative orthopedic rehabilitation is of great importance for the improvement of the patient's clinical condition. With the introduction of telerehabilitation services in recent years, it is possible for clinicians to monitor and manage the exercise protocols of their patients in a more practical, cost-effective and time-saving manner. Telerehabilitation is used in post-operative period for many pathological conditions, especially total knee arthroplasty, and its effectiveness is investigated by randomized controlled studies. In this review, exercise monitoring and management technologies in post-operative orthopedic rehabilitation process are discussed. Differences, similarities, advantages and disadvantages of these applications compared to conventional methods will be examined.

Key words: Orthopaedic Rehabilitation, Telerehabilitation, Exercise, Post-Operative.

\section{INTRODUCTION}

The positive results of physiotherapy and rehabilitation programs after orthopedic surgeries have been reported in many studies $(1,2)$. In this process, maximum clinical gain is tried to be achieved with rehabilitation protocols managed by clinicians. Disruptions in the rehabilitation programs may lead to deterioration in the patient's clinical condition. Delayed postoperative recovery is one of the most important problems in the field of orthopedic rehabilitation. The delayed process with postoperative complications contributes significantly to morbidity. Also, it may lead to hospital stay, increased mortality and reduced cost effectiveness (3). In recent years, cost increases and loss of time due to the increase in demand for rehabilitation services pose a threat to the sustainability of health services (4). Decreases in the cost of the internet and the increase in the availability of communication technologies in the 
community increased the opportunity to implement technology-based solutions. These developments were especially beneficial for the rehabilitation and maintenance of the people who were hospitalized after being discharged from the hospital. Technological solutions can increase patients' commitment to treatment, as well as reduce occupancy rates in hospitals and other healthcare providers (4-6). Especially with the revision of health policies due to aging in the populations of industrialized countries, deficiencies in the limited resources allocated to public health bring new searches. Telerehabilitation, which is one of the leading technological rehabilitation applications, is theoretically an efficient method that can be used in all areas where the rehabilitation process is applied. (5-7).

Telerehabilitation is defined as the remote provision of rehabilitation services through the use of telecommunication services (8). Telerehabilitation is used in patient assessment and education in many medical fields (9). The scientific community thinks that telerehabilitation increases the efficiency of rehabilitation services, especially in terms of sustainability. In addition, sustainability and applicability of the rehabilitation protocol are considered as an integral part of tele rehabilitation services $(9,10)$. Physiotherapists play an important role in exercise training before and after the surgery of orthopaedics. Exercise prescription is of great importance for the post-operative period (11). Telerehabilitation is one of the most important technological rehabilitation methods defined as remote provision of rehabilitation services such as exercise monitoring and management to patients using information and communication technologies (12). Telerehabilitation may include treatment parameters such as evaluation, training, follow-up and exercise. In the last few years, telerehabilitation services have developed rapidly. It considered as a low-cost alternative due to the possibility of reaching people in remote areas $(13,14)$.

Telerehabilitation provides positive benefits especially for individuals with travel barriers, who cannot come to hospital during working hours and cannot provide treatment and cannot provide continuity in exercise (15). The applicability and acceptability of this technology has been demonstrated by the increase in quality of life, patient and clinician satisfaction. Improvements in all these values are reported to be observed in terms of exercise monitoring and management in the field of physiotherapy and rehabilitation as well as in the post-operative period $(3,16)$. According to the results of a recent systematic review, it was stated that post-operative telerehabilitation practices in the field of orthopedic rehabilitation can yield promising results compared to traditional rehabilitation methods, in terms of pain and physical function. Also, it is concluded that exercise protocols should be seen as a viable option in holistic management (17). According to the results of the literature review, it is obvious that there are few narrative and systematic reviews that present the results of telerehabilitation studies, accordingly there is a lack of evidence about this subject.

In this review, current exercise monitoring and management technologies developed in the field of orthopedic rehabilitation will be explained. Limited number of randomized controlled studies have been conducted on this subject. In the post-operative period, the followup of the rehabilitation program with web-based platforms, patient education and patient specific exercise prescribing, and the ways of patient monitoring and management remotely will be discussed. Examples of different telerehabilitation technologies such as web-based platforms, video conference techniques, machine learning applications which can be considered as a new trend in medical technologies in the literature will be presented under for different 
patient groups. Advantages and disadvantages of telerehabilitation over conventional methods will be emphasized.

\section{LITERATURE REVIEW}

Telerehabilitation solutions allow clinicians to remotely monitor exercise programs of remote patients with technological systems. These applications are seen in many post-operative applications (18-20). In a randomized controlled pilot study, a new web-based platform improved the clinical situation with rehabilitation protocol after reconstruction surgery in individuals with anterior cruciate ligament injury. Participation in rehabilitation practices and monitoring of rehabilitation outcomes in these individuals were aimed. It has been argued that telerehabilitation is a way of supporting self-control in individuals. In this context, the feasibility of a three-month internet-based intervention mobile via the mobile site to increase recovery in patients following ACL reconstruction is assessed. The potential effects of webbased treatment applications on knee pain, function, self-efficacy and fear of pain were also investigated among the clinical results of the study. As a result of the study, no significant difference was found between the control group and the telerehabilitation group (21).

Successful post-operative telerehabilitation following total knee arthroplasty (THA) can provide successful results with telerehabilitation using synchronous (real-time) video. In a recent study, a randomized intervention study was performed following THA by comparing video-based software with conventional methods. Through the Capture Proof application, therapists presented a total of 23 videos of the same content as the training provided at the outpatient clinic. There was no statistical difference between groups in terms of recovery (22).

In the systematic review study in which telerehabilitation was performed in patients with total hip prosthesis, three clinical parameters, joint range of motion, coordination and compensation were examined as a result of telerehabilitation applications performed with the web platform. According to the results, it was stated that $88-91 \%$ agreement was observed between the evaluations made with the telerehabilitation system and the clinical evaluations made by the physiotherapists. It is also underlined when it is not entirely possible to perform all exercises performed in traditional physiotherapy with a telerehabilitation platform. This is thought to be due to inaccurate measurements of systems with improper calibration by low-cost systems implemented by image processing technologies and other inertial sensors. According to the conclusion of the review, telerehabilitation services can be used as a complement to traditional physical therapy (23).

According to the report of an ongoing study which was started to be performed with operated patients with subacromial impingement syndrome, the patients experienced pain, muscle weakness and loss of motion in the affected joint and the surgical operation had high success rates by telerehabilitation. It was emphasized that telerehabilitation applications showed positive results in some orthopedic conditions postoperatively, and therefore, it was stated that individual-specific telerehabilitation interventions should be developed to improve shoulder functions in patients with subacromial impingement syndrome. A treatment group receiving video exercise training and video conferencing through the web platform they developed was compared to the traditional physiotherapy field control group. The fact that such studies have been carried out for the last few years limits the available data (24). In their pilot 
study, it was emphasized that there was no difference between the two groups and that telerehabilitation was an effective intervention tool that could be used routinely (25).

In another project including a web platform developed for post-op patients after hip fractures, to increase the use of home-based rehabilitation and communication technologies aimed to contribute to the development of an improved rehabilitation process for patients with hip fractures and their relatives. In this study, it was aimed to design a multidisciplinary telerehabilitation protocol with a web-based platform and to compare this protocol with the conventional outpatient rehabilitation protocol at home and reported that the development studies are ongoing. Considering the increased incidence of hip fractures, it is emphasized that such rehabilitation technologies may be of great importance in the maintenance of rehabilitation for patients with acute hip fractures and disorders in post-operative period (26).

In a study in which cost analysis of telerehabilitation was performed in individuals with total knee arthroplasty, the importance telerehabilitation as an alternative service delivery method. Authors of the study mentioned as it became difficult to meet the demands of rehabilitation at home. To this end, they planned a randomized controlled trial comparing telerehabilitation and traditional rehabilitation methods. Telerehabilitation has implemented video conference sessions which they perform uninterrupted through high-speed internet connection for intervention. Compared with conventional rehabilitation, the cost of a single telerehabilitation session was lower or at the same level. They emphasized that stakeholders would consider these data to provide telerehabilitation in their clinics as services in their clinics (27).

In recent years, studies have been carried out to reduce health care costs in total hip arthroplasty. In one of these studies, the feasibility of a new artificial intelligence supported digital biofeedback system after total hip replacement was evaluated and compared with conventional methods (28). According to the results of this study, it is reported that this new solution reduces the dependence on human resources and provides better clinical results compared to traditional rehabilitation and it is promising to maintain treatment protocols after total hip arthroplasty (29).

The study evaluated the effect of anterior telerehabilitation program compared to normal surgical waiting before total knee and hip arthroplasty (30). According to the results of this pilot study, no significant difference was observed between the two groups and it was stated that this web platform could be used safely in individuals with arthroplasty (31). In a study conducted with patients with hip arthroplasty, it was stated that obstacles such as geographical location and transportation could limit access to appropriate health services and one of the solutions was rehabilitation programs that would be realized by saving money with telerehabilitation technologies. Telerehabilitation was performed via tablet to the telerehabilitation group, which was subjected to a similar exercise program as the conventional group. It was emphasized that the results were both cost effective and clinically effective (20).

In the artificial intelligence based telerehabilitation program developed for individuals with total knee arthroplasty, treatment management is carried out by providing feedback to patients with objective data from individuals. In the pilot study, data related to the platform they developed for remote patient management are presented. The results show that the system is effective. However, they reported that it should be supported by extensive studies with more cases (32). Recently, an application has been developed with artificial intelligence technology, 
which enables the monitoring of the patient's participation in home exercise programs in real time after lower extremity surgeries, monitoring the progress of rehabilitation of patients in the surgical team and receiving notification if there is a negative situation. A cohort pilot study of a total of 25 total knee arthroplasty patients demonstrated the ability of this technology to collect continuous data from each patient's smartphone. Technologies providing a remote patient monitoring system may allow surgeons to better evaluate postoperative rehabilitation and allow early intervention in emergencies such as complications (33).

\section{CONCLUSION}

It is seen that most of the telerehabilitation studies performed in the post-operative period of orthopedic rehabilitation are aimed at the monitoring and management of postarthroplasty treatment protocols. After the orthopedic surgery of many pathologies, especially total knee arthroplasty, telerehabilitation applications have started to be used in post-operative period patients. Particularly in recent years, randomized controlled studies have been performed, but the amount of data related to this is not sufficient in the literature. In most of these randomized controlled trials, it is observed that telerehabilitation is equivalent to conventional applications and there are no clinically significant differences between patients receiving telerehabilitation and those receiving conventional methods of treatment. In systematic review studies, gains from time and cost are emphasized through telerehabilitation services. It was stated that the patients' commitment to rehabilitation protocols and their communication with clinicians contributed to rehabilitation.

\section{REFERENCES}

1. Artz, N., Elvers, K. T., Lowe, C. M., Sackley, C., Jepson, P., \& Beswick, A. D. (2015). Effectiveness of physiotherapy exercise following total knee replacement: systematic review and meta-analysis. BMC Musculoskeletal Disorders, 16(1), 15.

2. Henderson, K. G., Wallis, J. A., \& Snowdon, D. A. (2018). Active physiotherapy interventions following total knee arthroplasty in the hospital and inpatient rehabilitation settings: a systematic review and meta-analysis. Physiotherapy, 104(1), 25-35.

3. Van Egmond, M. A., Van Der Schaaf, M., Vredeveld, T., Vollenbroek-Hutten, M. M. R., Van Berge Henegouwen, M. I., Klinkenbijl, J. H. G., et al. (2018). Effectiveness of physiotherapy with telerehabilitation in surgical patients: a systematic review and metaanalysis. Physiotherapy, 104(3), 277-298.

4. Ruiz-Fernandez, D., Marín-Alonso, O., Soriano-Paya, A., \& García-Pérez, J. D. (2014). eFisioTrack: a telerehabilitation environment based on motion recognition using accelerometry. The Scientific World Journal, 2014(1), 1-11.

5. Pastora-Bernal, J. M., Martín-Valero, R., Barón-López, F. J., \& Estebanez-Pérez, M. J. (2017). Evidence of benefit of telerehabitation after orthopedic surgery: a systematic review. Journal of Medical Internet Research, 19(4), 1-13.

6. Agostini, M., Moja, L., Banzi, R., Pistotti, V., Tonin, P., Venneri, A., et al. (2015). Telerehabilitation and recovery of motor function: a systematic review and metaanalysis. Journal of Telemedicine and Telecare, 21(4), 202-213. 
7. Rogante, M., Kairy, D., Giacomozzi, C., \& Grigioni, M. (2015). A quality assessment of systematic reviews on telerehabilitation: what does the evidence tell us? SciELO Public Health, 51(1), 11-18.

8. Dinesen, B., Nielsen, G., Andreasen, J. J., \& Spindler, H. (2019). Integration of rehabilitation activities into everyday life through telerehabilitation: qualitative study of cardiac patients and their partners. Journal of Medical Internet Research, 21(4), 1-14.

9. Theodoros, D., Russell, T., \& Latifi, R. (2008). Telerehabilitation: current perspectives. Studies in Health Technology and Informatics, 131(1), 191-210.

10. Scheideman-Miller, C., Clark, P. G., Moorad, A. L., Post, M. L., Hodge, B. G., \& Smeltzer, S. (2003). Efficacy and sustainability of a telerehabilitation program. Proceedings of the 36th Hawaii International Conference on System Sciences, 1(1), 111.

11. Hoogeboom, T. J., Dronkers, J. J., Hulzebos, E. H. J., \& van Meeteren, N. L. U. (2014). Merits of exercise therapy before and after major surgery. Current Opinion in Anaesthesiology, 27(2), 161.

12. Laver, K. E., Schoene, D., Crotty, M., George, S., Lannin, N. A., \& Sherrington, C. (2013). Telerehabilitation services for stroke. Cochrane Database of Systematic Reviews, 1(12), 3-20.

13. Ihrig, C. (2019). Travel cost savings and practicality for low-vision telerehabilitation. Telemedicine and e-Health, 25(7), 649-654.

14. Rogante, M., Grigioni, M., Cordella, D., \& Giacomozzi, C. (2010). Ten years of telerehabilitation: a literature overview of technologies and clinical applications. NeuroRehabilitation, 27(4), 287-304.

15. Beaver, K., Tysver-Robinson, D., Campbell, M., Twomey, M., Williamson, S., Hindley, A., et al. (2009). Comparing hospital and telephone follow-up after treatment for breast cancer: randomised equivalence trial. BMJ, 338(1), 1-9.

16. Huijgen, B. C. H., Vollenbroek-Hutten, M. M. R., Zampolini, M., Opisso, E., Bernabeu, M., Van Nieuwenhoven, J., et al. (2008). Feasibility of a home-based telerehabilitation system compared to usual care: arm/hand function in patients with stroke, traumatic brain injury and multiple sclerosis. Journal of Telemedicine and Telecare, 14(5), 249256.

17. Cottrell, M. A., Galea, O. A., O’Leary, S. P., Hill, A. J., \& Russell, T. G. (2017). Realtime telerehabilitation for the treatment of musculoskeletal conditions is effective and comparable to standard practice: a systematic review and meta-analysis. Clinical Rehabilitation, 31(5), 625-638.

18. Bashshur, R., Shannon, G., Krupinski, E., \& Grigsby, J. (2011). The taxonomy of telemedicine. Telemedicine and e-Health, 17(6), 484-494.

19. Kim K, Pham D, Schwarzkopf R. (2016). Mobile application use in monitoring patient adherence to perioperative total knee arthroplasty protocols. Surg Technol Int, 28(1), 253-60.

20. Nelson, M., Bourke, M., Crossley, K., \& Russell, T. (2017). Telerehabilitation versus traditional care following total hip replacement: a randomized controlled trial protocol. JMIR Research Protocols, 6(3), 1-9.

21. Levinger, P., Hallam, K., Fraser, D., Pile, R., Ardern, C., Moreira, B., et al. (2017). A novel web-support intervention to promote recovery following anterior cruciate ligament reconstruction: a pilot randomised controlled trial. Physical Therapy in Sport, 27(1), 29-37.

22. Bini, S. A., \& Mahajan, J. (2017). Clinical outcomes of remote asynchronous telerehabilitation are equivalent to traditional therapy following total knee arthroplasty: a randomized control study. Journal of Telemedicine and Telecare, 23(2), 239-247. 
23. Esparza, W., Aladro-Gonzalvo, A. R., Baldeon, J., \& Ortiz, S. (2019). Toward a design of a telerehabilitation program for the functional recovery in post-hip arthroplasty patients. E-book: IntechOpen.

24. Pastora-Bernal, J.-M., Martín-Valero, R., Barón-López, F. J., \& García-Gómez, O. (2017). Effectiveness of telerehabilitation programme following surgery in shoulder impingement syndrome (SIS): study protocol for a randomized controlled noninferiority trial. Trials, $18(1), 82$.

25. Pastora-Bernal, J. M., Martín-Valero, R., Barón-López, F. J., Moyano, N. G., \& Estebanez-Pérez, M. J. (2018). Telerehabilitation after arthroscopic subacromial decompression is effective and not inferior to standard practice: preliminary results. Journal of Telemedicine and Telecare, 24(6), 428-433.

26. Ortiz-Piña, M., Salas-Fariña, Z., Mora-Traverso, M., Martín-Martín, L., GalianoCastillo, N., García-Montes, et al. (2019). A home-based tele-rehabilitation protocol for patients with hip fracture called @ ctivehip. Research in Nursing \& Health, 42(1), 2938.

27. Tousignant, M., Moffet, H., Nadeau, S., Mérette, C., Boissy, P., Corriveau, H., et al. (2015). Cost analysis of in-home telerehabilitation for post-knee arthroplasty. Journal of Medical Internet Research, 17(3), 1-12.

28. Correia, F. D., Nogueira, A., Magalhães, I., Guimarães, J., Moreira, M., Barradas, I., et al. (2018). Home-based rehabilitation with a novel digital biofeedback system versus conventional in-person rehabilitation after total knee replacement: a feasibility study. Scientific Reports, 8(1), 1-12.

29. Correia, F. D., Nogueira, A., Magalhães, I., Guimarães, J., Moreira, M., Barradas, I., et al. (2019). Digital versus conventional rehabilitation after total hip arthroplasty: a single-center, parallel-group pilot study. JMIR Rehabilitation and Assistive Technologies, 6(1), 1-18.

30. Doiron-Cadrin, P., Kairy, D., Vendittoli, P. A., Lowry, V., Poitras, S., \& Desmeules, F. (2016). Effects of a tele-prehabilitation program or an in-person prehabilitation program in surgical candidates awaiting total hip or knee arthroplasty: protocol of a pilot single blind randomized controlled trial. Contemporary Clinical Trials Communications, 4(1), 192-198.

31. Doiron-Cadrin, P., Kairy, D., Vendittoli, P. A., Lowry, V., Poitras, S., \& Desmeules, F. (2020). Feasibility and preliminary effects of a tele-prehabilitation program and an inperson prehablitation program compared to usual care for total hip or knee arthroplasty candidates: a pilot randomized controlled trial. Disability and Rehabilitation, 42(7), 989-998.

32. Ramkumar, P. N., Haeberle, H. S., Ramanathan, D., Cantrell, W. A., Navarro, S. M., Mont, M. A., et al. (2019). Remote patient monitoring using mobile health for total knee arthroplasty: validation of a wearable and machine learning-based surveillance platform. The Journal of Arthroplasty, 34(10), 2253-2259.

33. Haeberle, H. S., Helm, J. M., Navarro, S. M., Karnuta, J. M., Schaffer, J. L., Callaghan, J. J., et al. (2019). Artificial intelligence and machine learning in lower extremity arthroplasty: a review. The Journal of Arthroplasty, 34(10), 2201-2203. 